\title{
Feasibility and outcome of an online streamed yoga intervention on stress and wellbeing of people working from home during COVID-19
}

\author{
Vipin Wadhen* and Tina Cartwright \\ Psychology, School of Social Sciences, University of Westminster, London, United Kingdom
}

Received 17 December 2020

Accepted 3 March 2021

\begin{abstract}
.
BACKGROUND: The outbreak of COVID-19 and its associated measures has resulted in a sizeable working population transitioning to working from home (WFH), bringing additional challenges, and increasing work-related stress. Research has indicated that yoga has promising potential in reducing stress in the workplace. However, there are very few studies exploring the impact of online streamed yoga on stress management for people-WFH.

OBJECTIVE: To investigate the feasibility and outcome of an online streamed yoga intervention on stress and wellbeing of people-WFH during COVID-19.

METHODS: A six-week pilot randomized controlled trial (RCT) yoga intervention was designed with yoga $(n=26)$ and a wait-list control group $(n=26)$. A mixed two-way ANOVA was used to assess changes in standardised outcome measures at baseline and post-intervention. Likert and open-ended questions assessed enjoyment, acceptability and perceived benefits of the program, which were analysed thematically.

RESULTS: Compared with the control, the yoga group reported significant improvements in perceived stress, mental wellbeing, depression and coping self-efficacy, but not stress and anxiety. Participants experienced physical and mental health benefits and reported high acceptability and enjoyment of the intervention.

CONCLUSIONS: An online yoga intervention can help people WFH manage stress and enhance wellbeing and coping abilities.
\end{abstract}

Keywords: Web-based, mind-body, mental-health, pandemic, remote-working

\section{Introduction}

The World Health Organization (WHO) defines work-related stress as "the response people may have when presented with work demands and pressures

\footnotetext{
*Address for correspondence: Vipin Wadhen, Psychology, School of Social Sciences, University of Westminster, 115 New Cavendish Street, London W1W6UW, United Kingdom. Tel.: +447308468129, +919717355306; E-mail: W1743122@my.westminster.ac.uk.
}

that are not matched to their knowledge and abilities and which challenge their ability to cope" [1, p.424]. In contrast wellbeing at work is defined as building an atmosphere to foster a state of contentment that enables employees to thrive and to realise their full potential for their own good and for their organisation [2]. Long-standing and unattended stress can have adverse effects on an employee's mental and physical health along with outcomes related to the organisation such as employee absenteeism, employee 
disability claims, and lost productivity [3]. Workplace stress has been consistently associated with cardiovascular disease [4, 5], psychosomatic problems, musculoskeletal disorders [6], mental health problems [7, 8], and non-adaptive HPA axis [9], cardiovascular [10] and immune responses [9].

Mental health in the workplace is increasingly a problem, and with 32.5 million people aged 16 to 64 in employment in the United Kingdom (UK), 75.3\% of its working population [11], the cost to the UK economy is estimated to be up to $£ 99$ billion each year [12]. Mental health problems have been deemed as having a more significant impact on people's ability to work in comparison to any other group of disorders [13].

In 2020, the American Psychological Association, revealed that $64 \%$ of employed adults reported work as a source of stress in the US with serious consequences for years to come due to COVID-19 [14]. Workplace stress is one of the most significant problems facing the organisations across Europe [15]. In 2019/20, 828,000 workers reported suffering from work related stress, depression or anxiety, which contributed to a loss of 17.9 million working days in the UK [16]. In the same period, work-related stress, anxiety or depression accounted for 51 per cent of all the cases of work-related ill health in Britain [16]. A survey $(n=1815)$ found that these numbers have exponentially increased, with $79 \%$ of British adults in employment commonly experiencing workrelated stress in 2020 [17]. One in eight of the current employees in the UK reported having a mental health condition, and $42 \%$ of employees felt their health condition affected their work a great deal or up to some extent [18].

Many non-pharmacological interventions have been tested to address the problem of workplace stress, including mind-body and mindfulness interventions. The literature related to mind-body stress reduction is continuously evolving in the field of workplace wellness and simultaneously in clinical populations. Several recent systematic reviews and meta-analyses have reported beneficial effects of mindfulness-based stress reduction (MBSR) interventions in improving mental health for employees at a workplace setting [19], nurses [21], psychological functioning of employees [20], and reducing stress in physicians and medical students [22]. However, several studies have also reported association of mindfulness/meditation with exacerbated mental health issues such as depression, anxiety, perceived stress and adverse effects like negativity, disorienta- tion, addiction to meditation, worsened relationships, and hypersensitivity [23-25]. MBSR interventions include mindfulness performance of hatha yoga postures as one of the components [26], with yoga demonstrating the most benefit in several populations $[27,28]$.

It is suggested that the practice of yoga is a natural way to engender mindfulness, as attention is focussed on the present moment, in part due to the intensity of the bodily sensations [19]. Poses (asana) are usually practised with slow controlled breathing which activates the parasympathetic response thereby inducing relaxation which helps an individual remain with the experience while simultaneously inhibiting negative cognitions [20]. It has been demonstrated that yogic breathing techniques (pranayama) can facilitate increased vagal tone also activating parasympathetic response [20]. Therefore, asana and pranayama can support mindfulness through body awareness as well as by strengthening positive neuroplasticity in higher brain structures [21].

Yoga is an ancient and comprehensive mindbody practice originating in India, encompassing all facets of the human existence: spirituality, psychology, philosophy and physiology [20]. It has gained in popularity mainly because of its therapeutic health benefits, both physical and mental [22-24]. Yoga-based practices such as postures, breathing techniques and meditation (dhyana) are defined as psychophysiological therapeutic practices that use several of these techniques inspired by a variety of yogic traditions [19]. There is accumulating research vouching for the promising potential of the therapeutic application of yoga in health management and mental health care. A few systematic reviews and meta-analyses have revealed positive effect of yoga interventions on mental health conditions [25, 26], structures and functions of brain [27], cardiometabolic health [28], menopausal symptoms [29], osteoarthritis [30], COPD [31], chronic non-specific neck pain [32], among other conditions.

The practise of yoga for therapeutic benefits is increasingly gaining popularity in the UK. A cross-sectional survey reported the perception of yoga as having a positive impact on mental and physical health conditions and an association with positive health behaviours [24]. Thus, based on everincreasing evidence, it is not surprising that research has indicated the potential of yoga in improving workplace stress and wellbeing. The National Institute for Health and Clinical Excellence (NICE) has 
recommended an increase in levels of physical activity at the workplace to improve wellbeing [33]. Increased physical activity has been found to have an association with lower job burnout, lower levels of depression [34] and lower physiological stress outside work [35]. A cohort study revealed that chronic workplace stress could lead to an increase in physical inactivity [36]. Moreover, several studies suggest that we have been living in a pandemic of physical inactivity and sedentary behaviour for many years [37-39], with COVID-19 threatening to increase this [40].

Yoga has demonstrated promising potential in combating stress in the workplace and increasing physical activity as evidenced by two recent systematic reviews. Della Valle and colleagues in their recent meta-analysis of six RCTs, found workplace yoga interventions to be more effective in comparison to no intervention in workplace stress management [41]. Puerto Valencia and colleagues in their systematic review of 13 RCTs revealed that yoga had a positive effect on health in the workplace, particularly in reducing stress, with no adverse effects reported [42]. Wolever and colleagues found that both mindfulnessbased, and therapeutic yoga programs could provide effective interventions in alleviating stress in employees [43]. A review of 56 studies found that workplace stress can also lead to musculoskeletal symptoms especially of back, neck and shoulders [44] and yoga can help deal with stress-induced musculoskeletal symptoms of the neck [45], back [46], and shoulders [47], among other symptoms.

The outbreak of COVID-19 and associated social distancing measures has resulted in a sizeable working population transitioning to working from home whilst concurrently managing family life, which can increase daytime stress, anxiety and depression levels, and also disrupt sleep [48]. A recent survey found additional challenges, such as lack of social contact, issues with work-life balance, and difficulty focusing; and for people with children younger than twelve the biggest challenges were increased household and care responsibilities [49]. Workplace stress 'pre-COVID-

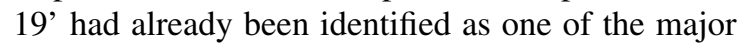
causes of low job performance, lack of motivation, low morale, low output and organisational sabotage [50]. Current circumstances have further accentuated this situation with new challenges like zoom fatigue (emotional and physical exhaustion caused by video conferencing), inability to unplug after office hours, difficulties communicating with colleagues, increased stress, and decreased mental health [48, 51-54].
The culture of homeworking was on gradual, although slow, rise even before lockdown in the UK. It tripled from $1.5 \%$ in 1981 to $4.7 \%$ in 2019 , but rose substantially during the lockdown with an eightfold rise from 5.7\% in January/February 2020 to $43.1 \%$ in April 2020 and even though there was decline by June 2020, it continues to remain high at $36.5 \%$ [55]. A survey from the British Council of Offices discovered that pandemic has changed working patterns for good with almost half of the employees (46\%) eager to split their time between homes and workplaces in future [56]. Another survey by the Institute of Directors revealed that three quarters of the directors predicted increased homeworking and more than half are planning to decrease their long-term use of workplaces [57]. One study also suggested that more than $40 \%$ of jobs can be performed at home in the UK [58]. Therefore, in the future, due to unpredictable circumstances of COVID-19 and inclination of both employers and employees toward a balanced approach, we may have a 'mixed' workforce working both 'on-site' and from home leading to long-term changes to working practices.

A yoga-based lifestyle has been recommended by the Government of India and various yoga organisations worldwide to help people remain healthy and promote optimal immune functions during the COVID-19 pandemic [59, 60]. In the wake of COVID-19 imposed social distancing measures, most of the fitness industry has moved to the online delivery of their programs, the popular virtual workouts app 'Mindbody' revealed yoga as the most popular virtual class booked with $32 \%$ of virtual bookings with an average of nearly 22,000 yoga bookings per day [61]. The delivery of mind-body programs online can help overcome barriers to participation because these programs can be accessed at convenient times, participants can work through recordings at their own pace, and maintain privacy [62]. Web-based interventions also offer benefits of cost-effectiveness for both participants and instructors related to traveling, high scalability and ease of access [63]. Nonetheless, there are some limitations of online yoga such as the lack of opportunities for instructors to adjust participants, lack of social connection, technical issues and difficulty in following the instructor [64].

There are, however, very few studies exploring the impact of the online mode of delivery or comparison with face-to-face ( $\mathrm{ftf}$ ) delivery. Research on online yoga is scant, more so on its potential to alleviate stress among people working from home. However, online mind-body interventions have been found 
to show promising potential in alleviating stress and enhancing wellbeing among various population groups. In a review and meta-analysis of 15 RCTs, Spijkerman and colleagues indicated the promising potential of online mind-body interventions in improving mental health outcomes, particularly stress in various population groups including employees [65]. Several other studies point to the benefits of online yoga interventions, including stress reduction and improved coping skills among nurse-midwives [66], a reduction of depression and grief in mothers who experienced stillbirth [64], improved physical and mental wellbeing in university students [67], and improved psychological outcomes in adults with cancer [68]. These studies also indicated the potential of the online mode of delivery to increase access, being convenient in terms of time and portability of devices e.g., smartphones, laptops or tablets and the opportunity to practise in privacy if desired.

Existing studies comparing $\mathrm{ftf}$ and online yoga/mindfulness interventions have found no differences in effectiveness or acceptability [43, 69]. Barak et al. (2008) in their comprehensive review and meta-analysis of internet-based psycho-therapeutic interventions, showed that there is no difference in effectiveness when compared to $\mathrm{ftf}$ interventions and in some cases internet-based interventions has been rated as superior by clients [70]. However, more research is needed to explore the acceptability and benefits of online yoga/mindfulness interventions in the context of working individuals. In the current circumstances of continued, changeable social distancing measures, it is pertinent to look at remote delivery of yoga interventions for people working from home.

One major limitation in evaluating yoga studies' impact on any physiological or psychological condition is non-consensus on dosage of intervention to achieve desired outcomes i.e., number of days and hours per week and duration of the intervention [71]. Wolever and Hartfiel in their separate workplace studies for stress reduction delivered a yoga intervention for 50 to 60 minutes weekly or twice weekly for eight to twelve weeks [43, 72]. Sherman (2012) reported a trend of classes in western studies lasting between 60 to 90 minutes - weekly or twice weekly [71]. However, a survey of 24 yoga teachers with expertise in applying yoga to address mental health conditions revealed that practice should consist of five 30-40 minutes sessions per week for at least six weeks for improving anxiety [73]. Traditional Yogic texts and scriptures also allude to the benefits of practice for longer durations and its regularity [74]. Therefore, it is possible that longer interventions with higher frequencies of classes per week could be beneficial for alleviating mental health conditions.

In summary, there are limitations in the current literature which this pilot study aims to address. The extant literature measuring the effects of online mode of delivery scarcely consider the workplace. Furthermore, all existing studies were conducted with nurses, students or patients rather than the general working population, with an inadequate explanation of yogic components (e.g., poses, breathing techniques, and meditation), their techniques (how they were performed?), and rationale (why they were performed?).

This study investigated whether an online streamed yoga intervention reduces stress and increases mental wellbeing in people working from home. It was hypothesized that online streamed yoga would lead to increase in mental wellbeing and coping self-efficacy and decreases in perceived stress, anxiety and depression compared with a control group. We also explored qualitatively yoga group participants' experiences of the intervention and the acceptability of an online synchronous program.

\section{Methods}

\subsection{Study design}

This pilot study used a randomized wait-list control design comparing pre-and post- (six-weeks) intervention scores between and within groups on validated outcome measures. Thematic analysis was performed on open ended questions to analyse prominent themes about participants' experiences and acceptability of the program.

\subsection{Participant recruitment}

The study received ethical approval from the University of Westminster (ETH1920-0764).

During May and June 2020, employees aged 18 and over, working from home were self-selected via emails sent out during weekly employee communication by corporate organizations and academic institutions based in London. Participant inclusion criteria were: 18 years or older, currently employed, speak and understand English and, not currently practising yoga. Participant exclusion criteria were: a physical/medical condition that would make practising 


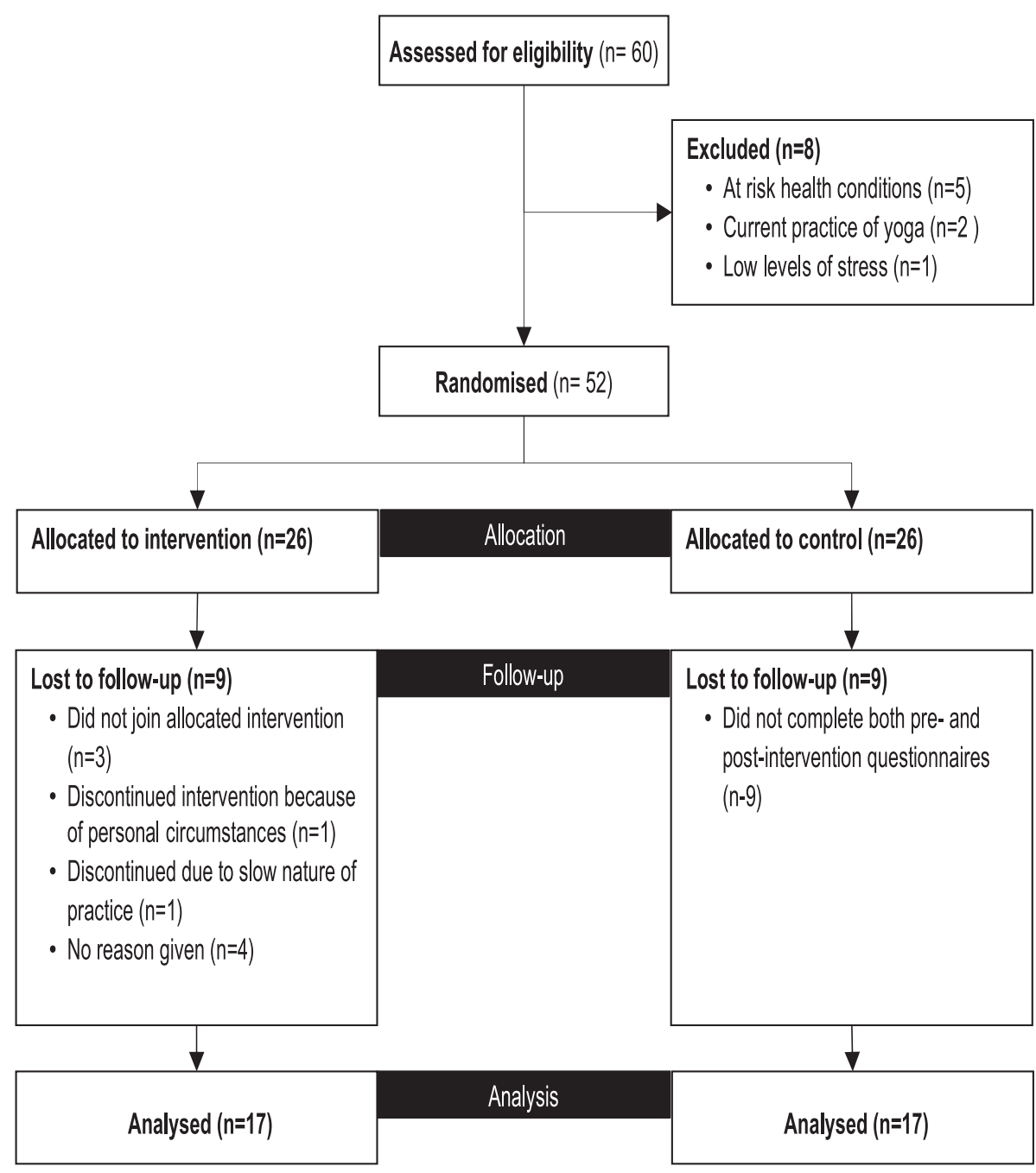

Fig. 1. Recruitment flow chart.

yoga unsafe or not possible, plans to take leave from work during the study and, current mental health diagnosis.

Interested employees were emailed a participant information sheet (PIS) which explained the purpose of the study, and a link to an online screening questionnaire. This invited participants to identify any health concerns from a list of 19 common conditions (e.g., arthritis, asthma, back pain, depression, anxiety, stress, heart conditions, etc.). Completed questionnaires were then assessed by the researcher, an experienced yoga practitioner. The questionnaire also asked participants to rate their self-identified stress levels on the scale of 1 to 10 and to indicate if they currently practice yoga or yoga-related activities. Participants who already practised yoga or yoga related activities were excluded from the study to prevent bias.

A total of 60 participants signed up for the study and 52 were electronically randomised into the yoga intervention $(n=26)$ or wait-list control group $(n=26)$ - Fig. 1. After randomisation, the intervention group was informed by email of class timings, Zoom meeting links and the nature of the sessions; the control group was informed of post-study Zoom meeting links and class timings by email and were asked not to practice yoga during the six-week period. Upon completion of the study, the control group received five yoga classes and a video of the program. Group membership was not blinded, and all classes were free of charge to participants. Outcome variables were measured at the beginning (baseline) and the 
end of the program (six weeks later). Informed consent was taken through the consent forms embedded with the baseline questionnaires through the Qualtrics link.

\subsection{Program delivery and attendance requirements}

This pilot study was conducted online through the Zoom online meeting platform with employees working for various organisations from home. Zoom is a video conferencing software that allows two or more people in different locations to communicate using audio and video imaging in real-time [75].

The 26 participants in the yoga intervention group were asked to attend a minimum of two and a maximum of three 50-minutes classes each week for six weeks (June/July 2020) led by the researcher who is a registered yoga teacher with eight years of experience. Participants could choose from any of the six classes scheduled per week via Zoom - three in the morning at 8 AM (Monday, Wednesday, and Friday) and three in the evening at 6 PM (Tuesday, Thursday, and Saturday). These timings were agreed after surveying eligible participants. Each participant also received a YouTube video link to a video recording and an instruction manual of the program to practice on their own, after the first week, to make up for any missed classes.

\subsection{Intervention design}

The Yoga program was informed by the tradition of Hatha Yoga and consisted of simplified and modified versions of various components such as poses, breathing techniques and relaxation/meditation techniques to suit the needs of the participants assessed using yoga screening questionnaire. The poses, breathing and relaxation components were selected on the basis of current research evidence in stress management and from yoga scriptures.

The inherent spiritual element of yoga was an important part of the intervention design. Taught yoga classes in modern western societies primarily focussed on potential physical and mental health benefits [71]; however, many scholars concur that decontextualization deconstructs the heart and spirit of yoga [76]. Authenticity was an important consideration in the design of the intervention and was in part, delivered through the chanting of Sanskrit prayers of togetherness in the beginning and fullness at the end. It was further enhanced by encouraging participants to find stillness and patience in the poses (asana) by holding them and focussing on the muscles engaged, pace of breath and thoughts arising in the mind. The scriptural origins and current scientific evidence supporting the selection of all program components is available on request.

\subsection{Class format}

The format of each class followed a consistent pattern: setting the mood, chanting (mantra-uchharan), joint movements (pawanmuktasana samuh), seated postures, standing postures, lying (supine) postures, breathing practices (pranayama) and relaxation through a short-guided meditation (dhyana) (see Table 1)

An instruction manual with a detailed explanation of each component was made available to participants and is available on request. A few minor modifications of the poses were introduced in week four to maintain the interest of the participants. There was a gradual progression from simpler version of poses to the actual poses. Alternate nostril breathing was introduced in the second week after participants learned right and left nostril breathing techniques. There was a progression throughout the program in gradually increasing the duration of each pose and introduction of minor variations.

\subsection{Measures}

Nine outcome measures were selected to assess baseline and post-intervention stress and wellbeing: Perceived stress (Perceived Stress Scale-14 items; PSS-14), Mental wellbeing (The Warwick-Edinburgh Mental Wellbeing Scale; WEMWBS), Coping selfefficacy (Coping Self-Efficacy Scale; CSES-26) and its three subscales - Problem focused coping, Stopping unpleasant thoughts \& emotions, Getting support from family \& friends, DASS (Depression, Anxiety \& Stress scale; DASS-21).

All four scales (PSS, WEMWBS, CSES and DASS), have demonstrated a substantial degree of concurrent validity and internal reliability [77-80].

The PSS is a 14-item scale, commonly used as a psychological instrument to measure the perception of stress, with seven positive items and seven negative items. It measures the extent to which a person perceives life situations as stressful. Participants are asked how often they experienced stress in the last month on a five-point Likert scale from 0 'never' 
Table 1

The hatha yoga intervention

\begin{tabular}{|c|c|}
\hline $\begin{array}{l}\text { Setting the mood } \\
(\text { Aarambh })\end{array}$ & $\begin{array}{l}\text { Mental preparation, focussing on the breath, Om chanting and peace } \\
\text { mantra (Shanti mantra). }\end{array}$ \\
\hline $\begin{array}{l}\text { Joint movement exercises } \\
\text { (Pawanmuktasana samuh) }\end{array}$ & $\begin{array}{l}\text { Foot, knee, pelvis, wrists, shoulders and neck movements aimed at } \\
\text { enhancing circulation, releasing tension and preparing the body for } \\
\text { movement. }\end{array}$ \\
\hline Postures (Asana) & $\begin{array}{l}\text { Ten postures (asana): } \\
\text { Butterfly pose (bhadrasana) } \\
\text { Seated spinal twists (tiryak sukhasana) } \\
\text { Cat pose (marjari asana) } \\
\text { Palm-tree pose (tadasana) } \\
\text { Cobra pose (bhujangasana) } \\
\text { Crocodile pose (makarasana) } \\
\text { Lying spinal twists (sansar asana) } \\
\text { Corpse pose (shavasana) } \\
\text { Seated forward fold (paschimottanasana) } \\
\text { Seated extended legs spinal twists (parshav dandasana) } \\
\text { All postures were performed slowly, with breath coordination, awareness } \\
\text { of muscles engaged and thoughts in mind. }\end{array}$ \\
\hline $\begin{array}{l}\text { Breathing practices } \\
\text { (Pranayama) }\end{array}$ & $\begin{array}{l}\text { Four yogic breathing techniques (pranayama): } \\
\text { Right nostril breathing } \\
\text { Left nostril breathing } \\
\text { Alternate nostril breathing } \\
\text { Bumble bee breath } \\
\text { All breathing practices were performed slowly, deeply and with long } \\
\text { inhalations and exhalations through the nose. }\end{array}$ \\
\hline $\begin{array}{l}\text { Relaxation - } 1 \\
\text { (Sithilikaran) }\end{array}$ & $\begin{array}{l}\text { Guided relaxation in corpse pose with an awareness of letting go of } \\
\text { tensions from the body through scanning from head to toes, followed by } \\
\text { slow and gentle abdominal breathing. }\end{array}$ \\
\hline $\begin{array}{l}\text { Relaxation }-2 \\
\text { (Sithilikaran) }\end{array}$ & $\begin{array}{l}\text { A guided relaxation sequence in easy pose (sukhasana), observing bodily } \\
\text { sensations and breath. }\end{array}$ \\
\hline Closing (Samapati) & $\begin{array}{l}\text { Easy pose (sukhasana) chanting of om three times and peace mantra } \\
\text { (shanti mantra). }\end{array}$ \\
\hline
\end{tabular}

to 4 'very often' e.g. "In the last month, how often have you felt that you were unable to control important things in your life?" Higher total scores indicate higher stress with possible scores ranging from 0 to 56 [81].

The WEMWBS is a 14-item scale used as a measure of mental wellbeing, focusing entirely on positive aspects of mental health [82]. It covers the broad picture of wellbeing, including affectiveemotional aspects, cognitive, evaluative dimensions and psychological functioning. The questionnaire collects data about the experiences of participants over the previous two weeks on 14 questions each answered on a five-point Likert scale from 1 'none of the time' to 5 'All of the time' Likert scale e.g. "I've been feeling optimistic about the future". Higher total scores indicate higher levels of mental wellbeing with possible scores ranging from 14 to 70 .

The CSES is a 26-item scale used as a measure of an individual's confidence in performing coping behaviours when faced with life challenges. It analyses coping self-efficacy through three subscales: use of problem-focused coping, stopping unpleas- ant emotions and thoughts and getting support from friends and family. Participants were asked, "when things aren't going well for you, or when you're having problems, how confident or certain are you that you can do the following?" The instrument collects data at any given point in time on an 11-point rating scale -0 to 10 with anchor points on the scale at 0 - 'cannot do at all'; 5 - 'moderately certain can do' and 10 - 'certainly can do' e.g. "look for something good in a negative situation" [77].

The DASS-21 is a shorter version of the DASS 42-item scale used as a measure of negative affect in adults (depression, anxiety and stress); seven items measure each factor. The instrument asks questions about physiological arousal, subjective awareness, low positive effect, along with a few other symptoms. It collects data on depression, anxiety and stress during the last week answered, ranging from 0 "Did not apply to me at all" to 4 "Applied to me very much or most of the time" e.g. I couldn't seem to experience any positive feelings at all [79]. The cut-off points for severity of each of the categories are described in Table 2: 
Table 2

DASS cut-off points

\begin{tabular}{lccc}
\hline Level/disorder & Depression & Anxiety & Stress \\
\hline Normal & $0-4$ & $0-3$ & $0-7$ \\
Mild & $5-6$ & $4-5$ & $8-9$ \\
Moderate & $7-10$ & $6-7$ & $10-12$ \\
Severe & $11-13$ & $8-9$ & $13-16$ \\
Extremely severe & $\geq 14$ & $\geq 10$ & $\geq 17$ \\
\hline
\end{tabular}

All four scales and their subscales demonstrated acceptable levels of internal consistency in our sample as determined by Cronbach's alpha levels $(\alpha)$ ranging from 0.70 to 0.97 .

Four open ended questions were asked to assess the overall experiences of the participants in taking part in the program such as perceived benefits, challenges, motivation to attend and acceptability of the online yoga program.

\section{Analysis}

\subsection{Quantitative analysis}

Quantitative analysis was performed using the IBM Statistical Package in the Social Sciences version 26. The data were checked for homogeneity of variances using Levene's test for equality of variances $(p>0.05)$, for outliers by boxplot, for normal distribution by Shapiro-Wilk's test of normality $(p>0.05)$ and for covariances by Box's M test $(p>0.001)$. Preand post-intervention data were compared using a 2 (Group) x 2 (Time) mixed-model ANOVA for PSS14, WEMWBS, all three domains of CSES and on all three domains of DASS-21. An independent $t$ test was performed to check baseline differences in yoga and control groups on the four outcome measures (PSS-14, WEMWBS, CSES and DASS-21). Only the CSES had any missing responses, where means were calculated providing at least $80 \%$ of questions were answered, following author guidelines [77,p424]. Significance was assessed at $p<0.05$ and false discovery rate (FDR) approach $(Q<0.05)$ was used to adjust the impact of yoga intervention on all domains, FDR is considered better alternative than traditional Bonferroni method [83].

\subsection{Qualitative analysis}

Responses were analysed inductively using thematic analysis based on an essential/realist epistemology [84]. A list of core themes was developed
Table 3

Characteristics of study participants

\begin{tabular}{lcc}
\hline $\begin{array}{l}\text { Demographic } \\
\text { information }\end{array}$ & $\begin{array}{c}\text { Yoga group } \\
(n=17)\end{array}$ & $\begin{array}{c}\text { Control group } \\
(n=17)\end{array}$ \\
\hline Mean age (SD) & 42.7 yrs. (10.94) & 42.2 yrs. (10.20) \\
\hline Gender & 17 & 14 \\
$\quad$ Women & 0 & 3 \\
Men & & \\
Occupation & 7 & 6 \\
Teaching & 5 & 5 \\
Corporate employees & 2 & 1 \\
Administration & 3 & 5 \\
Other & & \\
\hline
\end{tabular}

after reading answers to open-ended questions several times and coding them. One author (VW) appraised all responses and developed a list of codes and broader themes representing recurrent patterns in the data. Next, a senior qualitative researcher (TC), read through the data, reviewed all codes and broader themes. In the final stage, both researchers discussed each theme and subtheme, debating any discrepancies to agree on a final thematic structure. Two overarching themes were identified.

\section{Results}

\subsection{Quantitative analysis}

A total of 26 participants were randomised into the yoga and control groups. In the control group nine participants did not complete both the pre- and post-intervention questionnaires and were therefore excluded, leaving 17 participants for analysis. Of the 26 participants in the yoga intervention group, nine dropped out leaving 17 participants for analysis. Thirty-four participants were therefore included in the final analysis (see Fig. 1).

The mean age of the 34 participants was 42.5 years, $91 \%$ were women, $38 \%$ were teaching staff, $29 \%$ were corporate employees, $9 \%$ were employed in administrative roles and the remainder worked in other fields (see Table 3 ). The majority of participants worked full time $(M=37.2$ hours, $\mathrm{SD}=4.2)$.

All 17 participants in the yoga intervention group attended the minimum number of 12 recommended sessions during the six-week intervention period. The overall average attendance was 16.6 classes (live streamed classes plus home practice from video) over the six-week program; 2.7 classes per week. Ten participants (59\%) completed 18 classes, an average of three classes per week and seven participants (41\%) 
Table 4

Mean scores, F-ratios, Interaction $P$-values and Q-values from two-way mixed ANOVA analysis of PSS, WEMWBS, CSES and DASS

\begin{tabular}{|c|c|c|c|c|c|c|c|}
\hline \multirow[t]{2}{*}{ Domain } & \multicolumn{2}{|c|}{ Yoga intervention $(n=17)$} & \multicolumn{2}{|c|}{ Control $(n=17)$} & \multirow{2}{*}{\multicolumn{2}{|c|}{$\begin{array}{cc}\text { Interaction } \\
& \text { (Group x Time) } \\
p & p \text {-value } \\
\text { (unadjusted) }\end{array}$}} & \multirow[b]{2}{*}{$\begin{array}{l}\text { Q values } \\
\text { (adjusted) }\end{array}$} \\
\hline & $\begin{array}{l}\text { Pre-intervention } \\
\text { Mean (SD) }\end{array}$ & $\begin{array}{l}\text { Post-intervention } \\
\text { Mean (SD) }\end{array}$ & $\begin{array}{l}\text { Pre-intervention } \\
\text { Mean (SD) }\end{array}$ & $\begin{array}{l}\text { Post-intervention } \\
\text { Mean (SD) }\end{array}$ & & & \\
\hline Perceived stress (PSS) & $\mathbf{3 2 . 2 9}(8.37)$ & $23.47(8.56)$ & $29.41(8.03)$ & $28.12(7.66)$ & 10.30 & 0.003 & $<0.01$ \\
\hline $\begin{array}{l}\text { Mental wellbeing } \\
\text { (WEMWBS) }\end{array}$ & $41.59(7.18)$ & $49.76(6.55)$ & $42.76(7.06)$ & $44.24(7.32)$ & 9.84 & 0.004 & $<0.02$ \\
\hline $\begin{array}{l}\text { Coping self-efficacy } \\
\text { (CSES) }\end{array}$ & $122.24(39.90)$ & $167.29(48.12)$ & $147.47(44.89)$ & $139.76(45.35)$ & 10.63 & 0.003 & $<0.01$ \\
\hline $\begin{array}{l}\text { Problem focused } \\
\text { coping }\end{array}$ & $\mathbf{5 7 . 1 8}(19.48)$ & $80.65(20.33)$ & $72.35(19.05)$ & $\mathbf{6 8 . 3 5}(19.48)$ & 14.38 & 0.001 & $<0.005$ \\
\hline $\begin{array}{l}\text { Stopping unpleasant } \\
\text { thoughts \& emotions }\end{array}$ & $42.06(14.38)$ & $\mathbf{5 4 . 9 4}(20.12)$ & $47.00(18.53)$ & $44.82(17.81)$ & 5.22 & 0.029 & $<0.03$ \\
\hline $\begin{array}{l}\text { Getting support from } \\
\text { family \& friends }\end{array}$ & $23.00(9.95)$ & 31.71 (11.37) & $28.12(11.23)$ & $26.59(10.81)$ & 6.54 & 0.015 & $<0.02$ \\
\hline \multicolumn{8}{|l|}{$\begin{array}{l}\text { Depression, anxiety \& } \\
\text { stress (DASS) }\end{array}$} \\
\hline Depression & $6.53(2.98)$ & $\mathbf{3 . 0 6}(2.81)$ & $6.35(3.85)$ & $5.71(3.80)$ & 5.44 & 0.026 & $<0.03$ \\
\hline Anxiety & $4.47(2.98)$ & $2.53(2.37)$ & $4.06(2.79)$ & $\mathbf{3 . 7 6}(2.77)$ & 3.09 & NS & NS \\
\hline Stress & $10.18(4.09)$ & $6.47(2.42)$ & $9.59(3.60)$ & $8.06(3.63)$ & 3.12 & NS & NS \\
\hline
\end{tabular}

Significance values were determined after calculating FDR corrections for each domain [89].

completed more than 12 classes, an average of 2.4 classes per week.

An analysis of pre-intervention variable scores revealed no significant differences between the yoga and control groups as assessed by independent $t$ tests. Non-completers differed from completers on the demographic variable of age $(t=2.04, \mathrm{df}=24$, $p=0.05$ ): the mean age of completers was 42.7 years compared with 34.3 years for non-completers. There was no significant difference between completers and non-completers on any of the nine baseline outcome variables.

A significant interaction was obtained for all outcome measures with $p<0.05$ except for 'anxiety' and 'stress' (subscales of DASS). Analysis of mean scores also revealed significant improvements in seven outcome measures. This indicates that there were significant improvements in seven of the nine outcome measures for the yoga group compared to the control group from pre- to post-intervention (see Table 4).

A 2 (Group) x 2 (Time) mixed-model ANOVA revealed that the main effect of time was significant for seven of the nine outcome measures; it was not significant for 'stopping unpleasant thoughts and emotions' and 'seeking help from family and friends' (subscales of coping self-efficacy scale (CSES) which indicates improvements in outcome measures in both groups over time but more pronounced in the yoga group. The main effect of Group was non-significant for all outcome measures (see Table 5).
Table 5

Main effect $p$-values for PSS, WEMWBS, CSES and DASS

\begin{tabular}{lcc}
\hline & $\begin{array}{c}\text { Group } \\
\text { main } \\
\text { effect } \\
p \text {-value }\end{array}$ & $\begin{array}{c}\text { Time } \\
\text { main } \\
\text { effect } \\
p \text {-value }\end{array}$ \\
\hline Perceived stress (PSS) & NS & $\mathbf{0 . 0 0 1}$ \\
Mental wellbeing (WEMWBS) & NS & $\mathbf{0 . 0 0 1}$ \\
Coping self-efficacy (CSES) & NS & $\mathbf{0 . 0 2 8}$ \\
Problem focused coping & NS & $\mathbf{0 . 0 1 1}$ \\
Stopping unpleasant thoughts \& emotions & NS & NS \\
Getting support from family \& friends & NS & NS \\
Depression, anxiety \& stress (DASS) & & \\
Depression & NS & $\mathbf{0 . 0 0 2}$ \\
Anxiety & NS & $\mathbf{0 . 0 2 3}$ \\
Stress & NS & $\mathbf{0 . 0 0 1}$ \\
\hline
\end{tabular}

In summary, the two-way mixed ANOVA showed that in comparison to the control group, the yoga group reported significant reductions in perceived stress (PSS); depression; a significant improvement in mental wellbeing (WEMWBS); and coping selfefficacy (CSES); (see Figs. 2-5). An analysis of the individual domains within the CSES showed that the yoga group in comparison to the control group reported significant improvements in problem focussed coping, stopping unpleasant thoughts and emotions and in getting support from family and friends. Although non-significant, the yoga group also demonstrated feeling less stressed and anxious on DASS scale in comparison to the control group (see Table 4). 


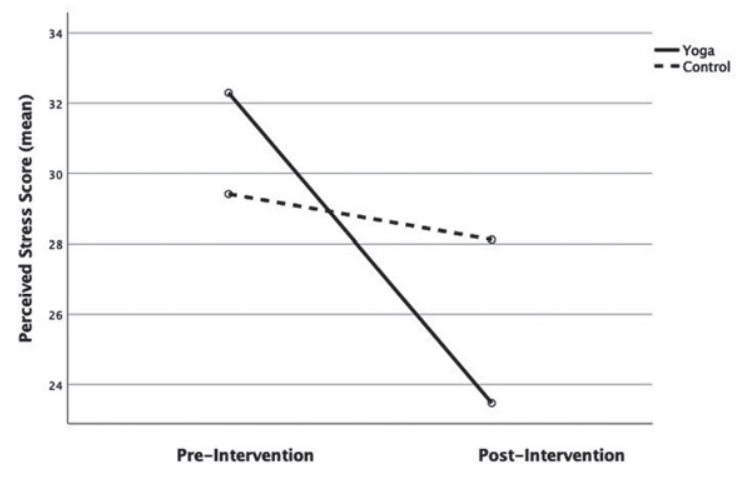

Fig. 2. Mean PSS scores. Pre-and post-intervention.



Fig. 3. Mean WEMWBS scores. Pre-and post-intervention.



Fig. 4. Mean CSES scores. Pre-and post-intervention.

An analysis of DASS cut-off scores revealed that at baseline only $17 \%$ of the participants had 'normal' levels of depression in the yoga group but this increased to $70 \%$ post-intervention. In contrast, in the control group, the percentage of participants with 'normal' levels of depression only increased from $29 \%$ to $35 \%$. 'Normal level' anxiety scores in the yoga group increased from $35 \%$ of participants at baseline to $70 \%$ post-intervention. However,

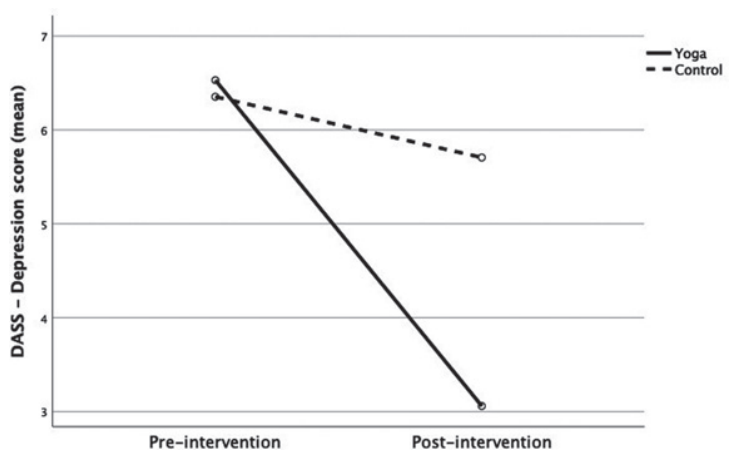

Fig. 5. Mean DASS scores. Pre-and post-intervention.

for the control group, 'normal level' anxiety scores declined from $52 \%$ to $47 \%$ of participants. 'Normal level' stress scores in the yoga group improved from $35 \%$ of participants at baseline to $64 \%(+29 \%)$ post-intervention. For the control group, 'normal level' stress scores also increased, from $23 \%$ to $47 \%(+24 \%)$ of participants. Mental wellbeing mean scores increased from 41.59 to $49.76(+8.17)$ for yoga participants. In comparison control group participants only showed an increase of 1.48 from 42.76 to 44.24 .

\subsection{Perceptions of yoga program}

Participants were asked several Likert-scale questions to assess the 'difficulty' and 'enjoyability' of the program, their 'willingness to continue' after the study and 'perceived improvements' in physical and mental health. Regarding 'difficulty' 10 of the 17 participants $(59 \%)$ found the program not at all difficult whereas 3 participants scored it 'a little difficult'. Regarding 'enjoyability', 94\% $(n=16)$ said that the program was 'extremely' or 'moderately' enjoyable. Regarding 'willingness to continue', $88 \%(n=15)$ said they were 'extremely' or 'moderately' likely to continue the practice. Regarding perceived improvements in physical and mental health, 76\% $(n=13)$ strongly or somewhat agreed that their physical health had improved; all 17 participants 'strongly or somewhat agreed' that their stress level had improved; and $88 \%(n=15)$ 'strongly or somewhat agreed' that their overall mental health had improved after the program. Seven participants (41\%) 'strongly' or somewhat agreed' that they had changed their lifestyle as a result of this yoga program. 


\subsection{Thematic analysis of participants' experiences}

Participants were asked four open-ended questions to assess their experiences of participation in the yoga program, from which two themes were identified:

1. Perceived impact of the program

2. Experiences of the program

Perceived impact of the program (see Table 6). Participants described a range of benefits they experienced as a result of participating in the program including physical health benefits (increased flexibility, improvements in existing pain, muscular stiffness and posture); stress-regulation (feeling less stressed, and discovering strategies to deal with stress); finding a personal oasis (time to stop and focus on oneself; regularity and stability to weekly/daily routine); a sense of calm and relaxation (feeling calmer, relaxed and emotionally balanced); self and body awareness (a sense of connection with oneself and sentience of areas of stiffness and positions in a deeper way).

Experiences of the program (see Table 7). Participants reported both general enjoyment of the program and specific components that they particularly enjoyed such as being led through relaxation and breathing practices. They also reflected upon the importance of the teacher to both motivate and encourage by creating a safe and supportive space to practice. Participants welcomed the convenience of the program being delivered online: the benefits of not having to travel and to practice from the comfort of their home; online links being straightforward to access and their surprise at being able to accommodate several classes each week. Participants also appreciated the flexibility of the class schedule that was offered throughout the week which facilitated attendance of the recommended number of classes.

Several participants commented upon the style and nature of the program. The majority reported an appropriate level of program progression and difficulty. Some reflected on their experience of a gentle form of yoga emphasizing slow and repetitive movements, which helped them experience the poses more deeply. Participants reported a range of challenges, including personal (difficulty in keeping eyes closed), program-specific (slow-repetitive movements being frustrating), technology-related (internet and connection problems) and platform-specific challenges (limitation of not being adjusted in poses or missing a sense of social connection due to online mode of delivery).

\section{Discussion}

To our knowledge, this is the first study that has explored the impact of an online streamed yoga intervention on stress and wellbeing of people working from home during COVID-19. It found that participants in the yoga intervention group reported significant reductions in perceived stress, depression and increases in mental wellbeing, coping selfefficacy and its three subscales: problem focussed coping, stopping unpleasant thoughts and emotions, and seeking help from family and friends, after the intervention. Although non-significant, scores on measures of stress and anxiety also reduced after the yoga intervention. In comparison, the waitlist control group did not show a significant improvement in any of the measures after six weeks. As ascertained by the thematic analysis of participants' experiences, the convenience of the online mode of delivery and high adherence to the program demonstrated the promising potential, acceptability and feasibility of an online streamed yoga intervention for stress alleviation of people working from home.

These findings are consistent with studies reporting the effects of $\mathrm{ftf}$ yoga interventions. In two separate studies, Hartfiel and colleagues found improvements in mood, resilience, psychological wellbeing, perceived stress and back-pain following a ftf yoga workplace intervention $[72,85]$. Similarly, a recent systematic review of 13 RCTs found positive mental health and stress reduction benefits of ftf yoga interventions, with nine of them using self-reported measures [42]. Our findings that coping self-efficacy increased after the intervention supported a previous pilot study of an online yoga intervention which improved coping skills and reduced stress in nursemidwives [66]. Several studies have found an association between increased coping and: better stress management, healthier employees [86], reduction in negative effects of job insecurity [87], high levels of buoyancy, wellbeing and engagement [88] and 'better' productivity [89]. These outcomes, along with those of the current study, are particularly salient for wellbeing officers and leaders of organizations in the current context of the volatile pandemic environment.

Several studies have demonstrated that $\mathrm{ftf}$ and online mind-body interventions are similar in terms of acceptance, effect and convenience [43, 69], with online interventions rated as superior in some cases [70].Together with the current findings, this supports the potential value of online interventions for organisations who support hybrid working (i.e. on- 
Table 6

Themes and sample quotes. Perceived impact of the program

\begin{tabular}{|c|c|c|}
\hline Sub-theme & $\begin{array}{l}\text { Number of } \\
\text { participants with } \\
\text { quotes falling } \\
\text { under the theme }\end{array}$ & Example quotes \\
\hline \multirow[t]{4}{*}{$\begin{array}{l}\text { Physical health } \\
\text { benefits }\end{array}$} & $\begin{array}{l}11 \text { participants, } \\
\text { all positive }\end{array}$ & $\begin{array}{l}\text { "My lower back pain and shoulder pain is gone. My digestion is better, and I am } \\
\text { less bloated." }\end{array}$ \\
\hline & & $\begin{array}{l}\text { "Practicing yoga has made me more supple, has relaxed my normally hunched } \\
\text { shoulders..." }\end{array}$ \\
\hline & & "I can see changes already in my physical flexibility..." \\
\hline & & $\begin{array}{l}\text { "Remarkably within almost } 3 \text { weeks of doing the breathing yoga I hardly } \\
\text { experienced the unexpected coughs and I could finally after } 4 \text { months lie down on } \\
\text { my back without coughing." }\end{array}$ \\
\hline \multirow[t]{5}{*}{ Stress regulation } & $\begin{array}{l}11 \text { participants, } \\
\text { all positive }\end{array}$ & "I also feel that I can face stressful situation with more assertiveness." \\
\hline & & "I have felt less overwhelmed and mentally over stimulated." \\
\hline & & "I have been less stressed and a lot calmer." \\
\hline & & $\begin{array}{l}\text { "I think this way of practising yoga has taught me some strategies to relax, } \\
\text { particularly through breathing techniques." }\end{array}$ \\
\hline & & "If I feel stressed, I practice the breathing techniques." \\
\hline \multirow[t]{4}{*}{ A personal oasis } & $\begin{array}{l}9 \text { participants; } \\
\text { all positive }\end{array}$ & $\begin{array}{l}\text { "It was good to put time aside to focus on myself and take myself away from } \\
\text { everything else." }\end{array}$ \\
\hline & & $\begin{array}{l}\text { "I loved having an hour of time devoted to myself and my well-being, where I knew } \\
\text { I could relax and re-set." }\end{array}$ \\
\hline & & "The thing I enjoyed most was the stability it brought to my weekly routine." \\
\hline & & "I found a new routine for my week, which enabled me to focus on me...." \\
\hline \multirow[t]{4}{*}{$\begin{array}{l}\text { Sense of calm and } \\
\text { relaxation }\end{array}$} & $\begin{array}{l}12 \text { participants; } \\
\text { all positive }\end{array}$ & "I feel much calmer." \\
\hline & & "I enjoyed the exercises and the sense of relaxation..." \\
\hline & & "I have felt a sense of peace and calmer emotional balance throughout the day." \\
\hline & & $\begin{array}{l}\text { "Through practicing the various breathing techniques, I really enjoyed the sense of } \\
\text { calm that ran through my body." }\end{array}$ \\
\hline \multirow[t]{4}{*}{$\begin{array}{l}\text { Self and body } \\
\text { awareness }\end{array}$} & $\begin{array}{l}10 \text { participants, } \\
\text { all positive }\end{array}$ & "I really enjoyed the feeling of connecting with myself." \\
\hline & & "The yoga practice helped me to be more in tune with my feelings of stress." \\
\hline & & "I became aware of some areas of stiffness (in my neck)." \\
\hline & & $\begin{array}{l}\text { "I liked to experience the positions in a deeper way, with a deeper sensation of } \\
\text { what is going on in my body." }\end{array}$ \\
\hline
\end{tabular}

site and from home). The qualitative findings from this study provide a deeper understanding of participant perceptions of an online program. The majority of participants responded positively to the style and nature of the yoga program by describing experiences of program being of the right style, level and progression. All participants found an online streamed yoga intervention highly convenient, flexible, enjoyable, 
Table 7

Themes and sample quotes. Experiences of the program

\begin{tabular}{ll}
\hline Theme & $\begin{array}{l}\text { Number of } \\
\text { participants with } \\
\text { quotes falling } \\
\text { under the theme }\end{array}$
\end{tabular}

Enjoyment 14 participants,

Example quotes

all positive

"I have enjoyed every session"

"I really enjoyed the gradual difficulty of the course; just right"

"I enjoyed the more "intense" stretching exercises the best such as laying down spinal twist and the folding forward while legs were straight."

"I enjoyed the breathing techniques most, I notice a difference after them."

"I liked being led through the relaxation of different areas of the body and found the reminder to relax parts of it that I wouldn't think of (like facial muscles, shoulders, etc.) really valuable."

Supportive teacher

Convenient and flexible platform/program

Style and nature of the yoga program

Challenges
10 participants; all positive

15 participants, all positive

9 participants, one negative
"I really enjoyed him as a teacher - he was very kind and welcoming and I felt I could reach out to him if I had questions."

"He was a great and engaging teacher"

"Teacher was amazing to listen to and easy to follow."

"He has created a very enjoyable and safe space for us all to be able to relax and completely surrender to the class."

"It was convenient in terms of already being at home, so not having to get anywhere to participate, I would have been far less likely to attend three classes a week had it been at a studio."

"The set up was perfect and always easy to connect and set up the contact to stream classes online together."

"The time of the session worked very well with my schedule and there were ample opportunity to switch timings if needed."

"I found online sessions very flexible and extremely convenient."

"So far I practiced a more dynamic kind of yoga, so I liked to experience the positions in a deeper way, with deeper sensation of what is going on in my body"

"the course was about my mind and trying to create a calmer state of mind, which the repetitive nature of the classes helped"

"the progression throughout the session from stillness to movement was perfectly set out"

"The slowness of this practice has been challenging at time because I was used to practising more dynamic yoga practices"

14 participants, "For some reason I always struggled holding the seating twists and had to lessen the twist in all negative order to stay for the full time but that was just a personal thing."

"It felt difficult not being able to be adjusted by teacher if need be."

"The only challenges I faced came from my technology - weak internet connections, computer updates, and so on that interrupted my practice."

"I am a very sociable persona and like social interaction which is hard to achieve in an online environment."

"I realized that I have a difficult time being in the moment and switching my brain off." 
creating a personal oasis, sense of calm and relaxation with self and body awareness and helpful in stress management as evidenced by both scales (PSS and WEMWBS) and thematic analysis.

These findings are consistent with previous yoga research where participants reported benefits such as mind-body awareness $[90,91]$, stress reduction $[41$, 42], and increased mental wellbeing [25]. Participants also noted the benefits of not having to travel and ease of access which is consistent with the findings of Heber and colleagues who found web-based interventions to be cost-effective in terms of travelrelated costs for both participants and instructor, high in scalability and easily accessible [63]. Therefore, there is promising potential for an online yoga intervention to offer a cost-effective and convenient tool for workplace managers to improve employee health and productivity, both during the current pandemic [92] and beyond.

The three limitations of an online yoga intervention identified in this research were technology-related (connectivity) problems, lack of social connection (two participants only), and the absence of physical adjustment by the instructor, consistent with previous findings [64]. Our program endeavoured to overcome this latter limitation by incorporating the same series of simple poses to develop self-efficacy in participants; with many reflecting how this enabled them to engage more deeply with the practice. Perceptions of social connection were mixed, with some participants reporting a sense of community, whilst others missed the opportunity to interact, consistent with findings from an international survey exploring the acceptability of online yoga during COVID-19 [93].

Adherence to the program was high, which could be due to a several factors. Participants were sent weekly emails to explain what they would experience and the purpose and philosophy of slow and gentle movements which may have contributed to high attendance and retention. Participants were also given the option to choose from a mix of evening and morning sessions delivered six times each week. However, this has cost implications if replicated in a larger trial. Qualitative findings suggest other potential motivating factors, such as providing a sense of stability to routine, enjoyment, feelings of being supported and held in a safe space, the convenience of using an online platform and experience of tangible benefits. Our findings are consistent with previous research which has found enjoyment, social support, the satisfaction experienced from physical activity, the convenience of access and rou- tine as important factors enhancing adherence and thus increasing the potential for health benefit in women [94-96].

The majority of participants discussed the use of breathing techniques in managing stress outside of the class and found them helpful. This is consistent with previous research where participants reported using breathing techniques to cope with stressful situations beyond the intervention [97, 98]. This ongoing uptake of breathing practices can help maintain the effects of yoga. Breathing techniques were reported as being both enjoyable and having the most notable impact on stress reduction and inducing a calmer state. Indeed, yogic breathing techniques have been found to show promising potential in managing stress [99-102]. Research has demonstrated that yoga breathing can modulate autonomic nervous system (ANS) function, stress responses, cardiac vagal tone, heart rate variability (HRV), central nervous system excitation, vigilance, attention, chemoreflex and baroreflex sensitivity, and neuroendocrine functions [103]. For most adults, slow breathing has been shown to optimally regulate the sympathovagal stress response [104-107]. An intervention solely focussed on pranayama (breathing) components of yoga could be beneficial for people with self-image issues who may be hesitant to engage in a postural class. A pranayama-only intervention could be delivered in a relatively shorter duration for stress management and represents an area for further research.

In addition to physiological mechanisms, psychological processes include increased mindfulness, interoceptive awareness, self-compassion, self-control and spiritual well-being [108]. These proposed mechanisms are concordant with our findings where participants described their perceptions of the program impact as increasing self and body awareness, finding a personal oasis, and a sense of calm and relaxation. Some researchers have suggested that yoga practice enhances coping mechanisms that allow practitioners to deal with stress more effectively, thereby reducing stress [109, 110]. This hypothesis is consistent with our finding of a significant increase in coping self-efficacy of yoga group participants in comparison to the control group after six weeks.

In this study, the sample was predominantly female (91\%) with no men in the yoga group, similar to Hartfiel et al.'s study ( $90 \%$ female) on yoga for workplace stress and back pain [46]. This reflects national survey data on yoga practice which consistently finds yoga 
practitioners are predominantly female [24]. However, a contrasting trend was observed in a survey in India, where practitioners were more likely to be men, perhaps due to cultural factors and the Indian origins of the discipline [111]. A similar trend was observed in Puerto Valencia et al.'s systematic review where the female majority studies were conducted in the west whilst male majority studies were conducted in India [42]. Given the potential benefits for health and wellbeing, it is important to identify ways to attract men to participate in mind-body interventions. Further research should be undertaken to better understand the perception of men toward yoga, ways to increase engagement and thereby increase uptake by men in future studies.

As with any study, there are limitations to this research which merit attention. This was a pilot study with small sample size; thus, it can only be considered preliminary work and warrants more extensive study. The sample was recruited through self-selection; therefore, it was representative of employees who were interested in online yoga for workplace stress management. The Hawthorne or placebo effects on the outcomes in the yoga group cannot be ruled out due to the waitlist nature of the control. There was no measurement of stressors affecting individuals during the intervention period - the control group showed a decrease in coping self-efficacy, which could have been due to stressors during pandemic uncertainty. This study only addressed short term impact of an online yoga program; it would be valuable to evaluate whether these changes could be maintained over a longer period of time and should be the focus of future research. 'Dosage' is an important factor that needs consideration. Sherman pointed at the non-consensus on optimum dosage for desired outcomes [71]. Further research could explore the optimum dosage for working populations who lack time to commit to longer interventions and/or a high frequency of weekly attendance. A long-term study could assess the continuing acceptability of attendance three times a week. A combination of subjective and objective measures such as heart rate variability (HRV), heart rate, blood pressure, and salivary cortisol should be used in future research to triangulate subjective and objective outcome measures.

Despite these limitations, the hypothesis that a six-week online yoga program will assist people working from home during COVID-19 in managing stress, improving mental wellbeing and enhancing coping self-efficacy was supported, and the findings are promising in terms of providing employers with a low-cost means to support the wellbeing of their employees who work from home. Furthermore, these findings are in no way restricted to people working from home - the intervention could be readily extended to employees working onsite and indeed, other population groups.

\section{Conclusion}

This study demonstrated not only the effectiveness but also the acceptability, feasibility and viability of a six week online streamed yoga intervention for stress reduction (of women) when working from home. Participants reported a wide range of benefits to health, wellbeing and stress-management from engaging in a yoga intervention delivered online in the stressful and unprecedented times of COVID-19.

\section{Acknowledgments}

The authors would like to express their gratitude to all participants for their time in taking part in the study.

\section{Conflict of interest}

None to declare.

\section{References}

[1] World Health Organization [ www.who.int ]. Stress at the workplace 2020 [updated 2020 June 14; cited 2020 July 16]. Available from: https://www.who.int/occupational_ health/topics/stressatwp/en/.

[2] The Chartered Institute of Personnel and Development [ https://www.cipd.co.uk/]. Wellbeing at work 2020 [updated 2020 April 20; cited 2020 August 3]. Available from: https://www.cipd.co.uk/knowledge/culture/wellbeing/factsheet\#19128.

[3] Mackey JD, Perrewé PL, McAllister CP. Do I fit in? Perceptions of organizational fit as a resource in the workplace stress process. Group \& Organization Management. 2017;42(4):455-86.

[4] Kivimäki M, Kawachi I. Work stress as a risk factor for cardiovascular disease. Current Cardiology Reports. 2015;17(9):74.

[5] Theorell T, Jood K, Järvholm LS, Vingård E, Perk J, Östergren PO, Hall C. A systematic review of studies in the contributions of the work environment to ischaemic heart disease development. The European Journal of Public Health. 2016;26(3):470-7. 
[6] Faragher E, Cass M, Cooper C. The relationship between job satisfaction and health: a meta-analysis. Occup Environ Med. 2005;62:105-12.

[7] Stansfeld S, Candy B. Psychosocial work environment and mental health-a meta-analytic review. Scandinavian Journal of Work, Environment \& Health. 2006:443-62.

[8] Theorell T, Hammarström A, Aronsson G, Bendz LT, Grape T, Hogstedt C, Marteinsdottir I, Skoog I, Hall C. A systematic review including meta-analysis of work environment and depressive symptoms. BMC Public Health. 2015;15(1):738.

[9] Eddy P, Heckenberg R, Wertheim EH, Kent S, Wright BJ. A systematic review and meta-analysis of the effort-reward imbalance model of workplace stress with indicators of immune function. Journal of Psychosomatic Research. 2016;91:1-8.

[10] Eddy P, Wertheim EH, Kingsley M, Wright BJ. Associations between the effort-reward imbalance model of workplace stress and indices of cardiovascular health: A systematic review and meta-analysis. Neuroscience \& Biobehavioral Reviews. 2017;83:252-66.

[11] Office for National Statistics. Employment in the UK: January 2021 [updated 2020 November 10; cited 2020 December 14]. Available from: https://www.ons.gov.uk/ employmentandlabourmarket/peopleinwork/employment andemployeetypes\#publications.

[12] UK Government. Thriving at Work: a review of mental health and employers 2017 [updated 2017 November 30; cited 2020 August 25]. Available from: https://www.gov.uk/government/publications/thriving-atwork-a-review-of-mental-health-and-employers.

[13] UK Government. Mental Health and Work 2013 [updated 2013 July 13; cited 2020 August 25]. Available from: https://assets.publishing.service.gov.uk/government/uplo ads/system/uploads/attachment_data/file/212266/hwwbmental-health-and-work.pdf.

[14] American Psychological Association [www.apa.org]. Stress in America 2020: A National Mental Health Crisis 2020 [updated 2020 October 22; cited 2020 November 24]. 1,7]. Available from: https://www.apa.org/news/ press/releases/stress/2020/sia-mental-health-crisis.pdf.

[15] Kelloway EK, Turner N, Barling J, Loughlin C. Transformational leadership and employee psychological well-being: The mediating role of employee trust in leadership. Work \& Stress. 2012;26(1):39-55.

[16] Health and Safety Executive. Work-related stress, anxiety or depression statistics in Great Britain, 2020 [updated 2020 March; cited 2020 August 25]. Available from: https://www.hse.gov.uk/statistics/causdis/stress.pdf.

[17] Perkbox. The 2020 UK workplace stress survey 2020 [updated 2020 March; cited 2020 August 25]. Available from: https://www.perkbox.com/uk/resources/library/ 2020-workplace-stress-survey.

[18] Public Health England. Workplace health: applying All Our Health 2019 [updated 2019 August 28; cited 2020 August 25]. Available from: https://www.gov.uk/ government/publications/workplace-health-applying-allour-health/workplace-health-applying-all-our-health

[19] Schmalzl L, Powers C, Henje Blom E. Neurophysiological and neurocognitive mechanisms underlying the effects of yoga-based practices: towards a comprehensive theoretical framework. Frontiers in Human Neuroscience. 2015;9:235.

[20] Gard T, Noggle JJ, Park CL, Vago DR, Wilson A. Potential self-regulatory mechanisms of yoga for psycho- logical health. Frontiers in Human Neuroscience. 2014; 8:770.

[21] Mason H, Birch K. Yoga for Mental Health: For Yoga Teachers, Therapists, and Mental Health Professionals: Handspring Publishing; 2018.

[22] Birdee GS, Legedza AT, Saper RB, Bertisch SM, Eisenberg DM, Phillips RS. Characteristics of yoga users: Results of a national survey. Journal of General Internal Medicine. 2008;23(10):1653-8.

[23] Quilty MT, Saper RB, Goldstein R, Khalsa SBS. Yoga in the real world: Perceptions, motivators, barriers, and patterns of use. Global Advances in Health and Medicine. 2013;2(1):44-9.

[24] Cartwright T, Mason H, Porter A, Pilkington K. Yoga practice in the UK: a cross-sectional survey of motivation, health benefits and behaviours. BMJ Open. 2020; 10(1).

[25] Domingues R. Modern postural yoga as a mental health promoting tool: A systematic review. Complementary Therapies in Clinical Practice. 2018;31:248-55.

[26] Pascoe MC, Thompson DR, Ski CF. Yoga, mindfulnessbased stress reduction and stress-related physiological measures: A meta-analysis. Psychoneuroendocrinology. 2017;86:152-68.

[27] Gothe N, Khan I, Hayes J, Erlenbach E, Damoiseaux J. Yoga Effects on Brain Health: A Systematic Review of the Current Literature. Brain Plasticity (Amsterdam, Netherlands). 2019;5(1):105-22.

[28] Chu P, Gotink RA, Yeh GY, Goldie SJ, Hunink MM. The effectiveness of yoga in modifying risk factors for cardiovascular disease and metabolic syndrome: A systematic review and meta-analysis of randomized controlled trials. European Journal of Preventive Cardiology. 2016;23(3):291-307.

[29] Cramer H, Peng W, Lauche R. Yoga for menopausal symptoms-A systematic review and meta-analysis. Maturitas. 2018;109:13-25.

[30] Lauche R, Hunter D, Adams J, Cramer H. Yoga for Osteoarthritis: a Systematic Review and Meta-analysis. Current Rheumatology Reports. 2019;21(9):47.

[31] Cramer, H, Haller H, Klose P, Ward L, Chung V, Lauche $R$. The risks and benefits of yoga for patients with chronic obstructive pulmonary disease: a systematic review and meta-analysis. Clinical Rehabilitation. 2019;33(12):1847.

[32] Li Y, Li S, Jiang J, Yuan S. Effects of yoga on patients with chronic nonspecific neck pain: A prisma systematic review and meta-analysis. Medicine. 2019;98(8).

[33] National Institute for Health and Clinical Excellence [www.nice.org.uk]. Physical activity: encouraging activity in the community 2019 [updated 2020 June 06; cited 2020 August 25]. Available from: https://www.nice.org.uk/ guidance/qs183/resources/physical-activity-encouragingactivity-in-the-community-pdf-75545719693765.

[34] Toker S, Biron M. Job burnout and depression: unraveling their temporal relationship and considering the role of physical activity. Journal of Applied Psychology. 2012;97(3):699.

[35] Lindberg CM, Srinivasan K, Gilligan B, Razjouyan J, Lee H, Najafi B, Mehl MR, Currim F, Ram S, Lunden MM. Effects of office workstation type on physical activity and stress. Occupational and Environmental Medicine. 2018;75(10):689-95.

[36] Kouvonen A, Vahtera J, Oksanen T, Pentti J, Väänänen AK, Heponiemi T, Salo P, Virtanen M, Kivimäki M. Chronic workplace stress and insufficient physical activ- 
ity: a cohort study. Occupational and Environmental Medicine. 2013;70(1):3-8.

[37] Kohl 3rd HW, Craig CL, Lambert EV, Inoue S, Alkandari JR, Leetongin G, Kahlmeier S, Group LPASW. The pandemic of physical inactivity: global action for public health. The Lancet. 2012;380(9838):294-305.

[38] Ozemek C, Lavie CJ, Rognmo Ø. Global physical activity levels-Need for intervention. Progress in Cardiovascular Diseases. 2019;62(2):102-7.

[39] Pratt M, Varela AR, Salvo D, Kohl Iii HW, Ding D. Attacking the pandemic of physical inactivity: what is holding us back? : BMJ Publishing Group Ltd and British Association of Sport and Exercise Medicine; 2020.

[40] Hall G, Laddu D, Phillips S, Lavie C, Arena R. A tale of two pandemics: How will COVID-19 and global trends in physical inactivity and sedentary behavior affect one another? Progress in Cardiovascular Diseases. 2020.

[41] Della Valle E, Palermi S, Aloe I, Marcantonio R, Spera R, Montagnani S, Sirico F. Effectiveness of Workplace Yoga Interventions to Reduce Perceived Stress in Employees: A Systematic Review and Meta-Analysis. Journal of Functional Morphology and Kinesiology. 2020;5(2):33.

[42] Puerto Valencia L, Weber A, Spegel H, Bögle R, Selmani A, Heinze S, Herr C. Yoga in the workplace and health outcomes: a systematic review. Occupational Medicine. 2019;69(3):195-203.

[43] Wolever RQ, Bobinet KJ, McCabe K, Mackenzie ER, Fekete E, Kusnick CA, Baime M. Effective and viable mind-body stress reduction in the workplace: a randomized controlled trial. Journal of Occupational Health Psychology. 2012;17(2):246.

[44] Bongers PM, de Winter CR, Kompier MA, Hildebrandt VH. Psychosocial factors at work and musculoskeletal disease. Scandinavian Journal of Work, Environment \& Health. 1993:297-312.

[45] Cramer H, Lauche R, Hohmann C, Lüdtke R, Haller H, Michalsen A, Langhorst J, Dobos G. Randomizedcontrolled trial comparing yoga and home-based exercise for chronic neck pain. The Clinical Journal of Pain. 2013;29(3):216-23.

[46] Hartfiel N, Burton C, Rycroft-Malone J, Clarke G, Havenhand J, Khalsa S, Edwards R. Yoga for reducing perceived stress and back pain at work. Occupational Medicine. 2012;62(8):606-12.

[47] Eyigor S, Uslu R, Apaydın S, Caramat I, Yesil H. Can yoga have any effect on shoulder and arm pain and quality of life in patients with breast cancer? A randomized, controlled, single-blind trial. Complementary Therapies in Clinical Practice. 2018;32:40-5.

[48] Altena E, Baglioni C, Espie C, Ellis J, Gavriloff D, Holzinger B, Schlarb A, Frase L, Jernelöv S, Riemann D. Dealing with sleep problems during home confinement due to the COVID-19 outbreak: practical recommendations from a task force of the European CBT-I Academy. Journal of Sleep Research. 2020.

[49] Rubin O, Nikolaeva A, Nello-Deakin S, te Brömmelstroet M. What can we learn from the COVID-19 pandemic about how people experience working from home and commuting. Centre for Urban Studies, University of Amsterdam Working Paper. 2020.

[50] Ismail A, Saudin N, Ismail Y, Samah AJA, Bakar RA, Aminudin NN. Effect of workplace stress on job performance. Economic Review: Journal of Economics and Business. 2015;13(1):45-57.
[51] Fosslien L, Duffy MW. How to combat zoom fatigue. Harvard Business Review. 2020;29.

[52] Hayes S, Priestley JL, Ishmakhametov N, Ray HE. "I'm not Working from Home, I'm Living at Work": Perceived Stress and Work-Related Burnout before and during COVID-19. 2020.

[53] Routley N, editor 6 charts that show what employers and employees really think about remote working. World Economic Forum: https://wwwweforumorg/agenda/2020/06/ coronavirus-covid19-remote-working-office-employeesemployers; 2020.

[54] Toniolo-Barrios M, Pitt L. Mindfulness and the challenges of working from home in times of crisis. Business Horizons. 2020.

[55] Felstead A, Reuschke D. Homeworking in the UK: Before and During the 2020 Lockdown. 2020.

[56] The British Council of Offices. Majority of workers plan a return to the office, but home working here to stay 2020 [updated 2020 October 05; cited 2020 October 22]. Available from: http://www.bco.org.uk/News/ News46982.aspx.

[57] The Institute of Directors. Home-working here to stay 2020 [updated 2020 October 05; cited 2020 October 22]. Available from: https://www.iod.com/news/news/articles/ Home-working-here-to-stay-new-IoD-figures-suggest.

[58] Dingel JI, Neiman B. How many jobs can be done at home? : National Bureau of Economic Research; 2020. Report No.: 0898-2937.

[59] Ministry of Ayush [ www.ayush.gov.in]. Ayurveda's immunity boosting measures for self care during COVID 19 crisis. 2020 [updated 2020 April 07; cited 2020 July 15]. Available from: https://www.ayush.gov.in/docs/123.pdf.

[60] Sharma K, Anand A, Kumar R. The role of Yoga in working from home during the COVID-19 global lockdown. Work. 2020(Preprint):1-7.

[61] Forbes [ www.forbes.com ]. How COVID-19 is transforming the fitness industry 2020 [updated 2020 July 13; cited 2020 July 22]. Available from: https://www.forbes.com/ sites/jesscording/2020/07/13/covid-19-transformingfitness-industry/\#44ba9bff30a7.

[62] Nguyen MC, Gabbe SG, Kemper KJ, Mahan JD, Cheavens JS, Moffatt-Bruce SD. Training on mind-body skills: Feasibility and effects on physician mindfulness, compassion, and associated effects on stress, burnout, and clinical outcomes. The Journal of Positive Psychology. 2020;15(2):194-207.

[63] Heber E, Ebert DD, Lehr D, Cuijpers P, Berking M, Nobis $\mathrm{S}$, Riper $\mathrm{H}$. The benefit of web-and computer-based interventions for stress: a systematic review and meta-analysis. Journal of Medical Internet Research. 2017;19(2):e32.

[64] Huberty J, Sullivan M, Green J, Kurka J, Leiferman J, Gold K, Cacciatore J. Online yoga to reduce post traumatic stress in women who have experienced stillbirth: a randomized control feasibility trial. BMC Complementary Medicine \& Therapies. 2020;20(1).

[65] Spijkerman M, Pots W, Bohlmeijer E. Effectiveness of online mindfulness-based interventions in improving mental health: A review and meta-analysis of randomised controlled trials. Clinical Psychology Review. 2016.

[66] Wright EM. Evaluation of a web-based holistic stress reduction pilot program among nurse-midwives. Journal of Holistic Nursing. 2018;36(2):159-69.

[67] Strahm MF, Cohen M, Borg-Olivier S. University-based online yoga education: A pilot study of students' experience. Int J Yoga. 2016;9(1):86. 
[68] Addington EL, Sohl SJ, Tooze JA, Danhauer SC. Convenient and Live Movement (CALM) for women undergoing breast cancer treatment: Challenges and recommendations for internet-based yoga research. Complementary Therapies in Medicine. 2018;37:77-9.

[69] Martini A, Hammer K, Heller B, Hirshfeld-Cytron J. The impact of in-person and online structured yoga programs on anxiety levels in patients after in vitro fertilization (IVF) failure: a preliminary analysis. Fertility and Sterility. 2017;108(3):e301.

[70] Barak A, Hen L, Boniel-Nissim M, Shapira Na. A comprehensive review and a meta-analysis of the effectiveness of internet-based psychotherapeutic interventions. Journal of Technology in Human Services. 2008;26(2-4): 109-60.

[71] Sherman KJ. Guidelines for developing yoga interventions for randomized trials. Evidence-Based Complementary and Alternative Medicine. 2012;2012.

[72] Hartfiel N, Burton C, Rycroft-Malone J, Clarke G, Havenhand J. Yoga for reducing perceived stress and back pain at work. Occupational Medicine (Oxford). 2012;62(8):60612.

[73] de Manincor M, Bensoussan A, Smith C, Fahey P, Bourchier S. Establishing key components of yoga interventions for reducing depression and anxiety, and improving well-being: a Delphi method study. BMC Complementary and Alternative Medicine. 2015;15(1):85.

[74] Iyengar BKS. Light on the yoga sutras of Patanjali: Aquarian/Thorsons; 1993.

[75] Gray LM, Wong-Wylie G, Rempel GR, Cook K. Expanding qualitative research interviewing strategies: Zoom video communications. The Qualitative Report. 2020;25(5):1292-301.

[76] Cook-Cottone C. Dosage as a critical variable in yoga therapy research. International Journal of Yoga Therapy. 2013(23): 11

[77] Chesney MA, Neilands TB, Chambers DB, Taylor JM, Folkman S. A validity and reliability study of the coping self-efficacy scale. British Journal of Health Psychology. 2006;11(3):421-37.

[78] Cohen J, Cohen P, West SG, Aiken LS. Applied multiple regression/correlation analysis for the behavioral sciences: Routledge; 2013.

[79] Lovibond PF, Lovibond SH. The structure of negative emotional states: Comparison of the Depression Anxiety Stress Scales (DASS) with the Beck Depression and Anxiety Inventories. Behaviour Research and Therapy. 1995;33(3):335-43.

[80] Tennant R, Hiller L, Fishwick R, Platt S, Joseph S, Weich S, Parkinson J, Secker J, Stewart-Brown S. The Warwick-Edinburgh mental well-being scale (WEMWBS): development and UK validation. Health and Quality of life Outcomes. 2007;5(1):63.

[81] Cohen S, Kamarck T, Mermelstein R. A global measure of perceived stress. Journal of Health and Social Behavior. 1983:385-96.

[82] Stewart-Brown SL, Platt S, Tennant A, Maheswaran H, Parkinson J, Weich S, Tennant R, Taggart F, Clarke A. The Warwick-Edinburgh Mental Well-being Scale (WEMWBS): a valid and reliable tool for measuring mental well-being in diverse populations and projects. J Epidemiol Community Health. 2011;65(Suppl 2): A38-A9.

[83] Benjamini Y, Hochberg Y. Controlling the false discovery rate: a practical and powerful approach to multiple testing. Journal of the Royal statistical society: series B (Methodological). 1995;57(1):289-300.

[84] Braun V, Clarke V. Using thematic analysis in psychology. Qualitative Research in Psychology. 2006;3(2): 77-101.

[85] Hartfiel N, Havenhand J, Khalsa SB, Clarke G, Krayer A. The effectiveness of yoga for the improvement of well-being and resilience to stress in the workplace. Scandinavian Journal of Work, Environment \& Health. 2011:70-6.

[86] Holton M, Barry A, Chaney J. Employee stress management: An examination of adaptive and maladaptive coping strategies on employee health. Work (Reading, Mass). 2015;53(2):299.

[87] Cheng T, Mauno S, Lee C. The buffering effect of coping strategies in the relationship between job insecurity and employee well-being. Economic and Industrial Democracy. 2014;35(1):71-94.

[88] Parker PD, Martin AJ. Coping and buoyancy in the workplace: Understanding their effects on teachers' workrelated well-being and engagement. Teaching and Teacher Education. 2009;25(1):68-75.

[89] Agbonluae OO, Omi-Ujuanbi G, Akpede M. Coping strategies for managing occupational stress for improved worker productivity. IFE PsychologIA: An International Journal. 2017;25(2):300-9.

[90] Mehling WE, Wrubel J, Daubenmier JJ, Price CJ, Kerr CE, Silow T, Gopisetty V, Stewart AL. Body Awareness: a phenomenological inquiry into the common ground of mind-body therapies. Philosophy, Ethics, and Humanities in Medicine. 2011;6(1):6.

[91] Tihanyi BT, Böôr P, Emanuelsen L, Köteles F. 'Mediators between Yoga Practice and Psychological Well-Being: Mindfulness, Body Awareness and Satisfaction with Body Image'. European Journal of Mental Health. 2016;11(12):112.

[92] Lopez-Leon S, Forero DA, Ruiz-Díaz P. Recommendations for working from home during the pandemic (and Beyond). Work. 2020(Preprint):1-5.

[93] Metcalf L, Cartwright T. An investigation into the benefits, barriers and acceptability of online yoga. (in preparation).

[94] Huberty JL, Ransdell LB, Sidman C, Flohr JA, Shultz B, Grosshans O, Durrant L. Explaining long-term exercise adherence in women who complete a structured exercise program. Research Quarterly for Exercise and Sport. 2008;79(3):374-84.

[95] McArthur D, Dumas A, Woodend K, Beach S, Stacey D. Factors influencing adherence to regular exercise in middle-aged women: a qualitative study to inform clinical practice. BMC Women's Health. 2014;14(1):49.

[96] White JL, Randsdell LB, Vener J, Flohr JA. Factors related to physical activity adherence in women: review and suggestions for future research. Women \& Health. 2005;41(4):123-48.

[97] Kjellgren A, Bood SÅ, Axelsson K, Norlander T, Saatcioglu F. Wellness through a comprehensive Yogic breathing program-A controlled pilot trial. BMC Complementary and Alternative Medicine. 2007;7(1):43.

[98] Tellhed U, Daukantaite D, Maddux RE, Svensson T, Melander O. Yogic Breathing and Mindfulness as Stress Coping Mediate Positive Health Outcomes of Yoga. Mindfulness. 2019;10(12):2703-15.

[99] Peterson CT, Bauer SM, Chopra D, Mills PJ, Maturi RK. Effects of shambhavi mahamudra kriya, a multicomponent breath-based yogic practice (Pranayama), on perceived 
stress and general well-being. Journal of Evidence-Based Complementary \& Alternative Medicine. 2017;22(4): 788-97.

[100] Sharma VK, Trakroo M, Subramaniam V, Rajajeyakumar M, Bhavanani AB, Sahai A. Effect of fast and slow pranayama on perceived stress and cardiovascular parameters in young health-care students. International Journal of Yoga. 2013;6(2):104.

[101] Zope SA, Zope RA. Sudarshan kriya yoga: Breathing for health. International Journal of Yoga. 2013;6(1):4.

[102] Hepburn S-J, McMahon M. Pranayama meditation (yoga breathing) for stress relief: is it beneficial for teachers? The Australian Journal of Teacher Education. 2017;42(9):14259.

[103] Brown RP, Gerbarg PL. Yoga breathing, meditation, and longevity. Annals of the New York Academy of Sciences. 2009;1172(1):54.

[104] Bernardi L, Porta C, Gabutti A, Spicuzza L, Sleight P. Modulatory effects of respiration. Autonomic Neuroscience. 2001;90(1-2):47-56.

[105] Lehrer P, Karavidas MK, Lu S-E, Coyle SM, Oikawa LO, Macor M, Calvano SE, Lowry SF. Voluntarily produced increases in heart rate variability modulate autonomic effects of endotoxin induced systemic inflammation: an exploratory study. Applied Psychophysiology and Biofeedback. 2010;35(4):303-15.
[106] Song H-S, Lehrer PM. The effects of specific respiratory rates on heart rate and heart rate variability. Applied Psychophysiology and Biofeedback. 2003;28(1):13-23.

[107] Vaschillo EG, Vaschillo B, Lehrer PM. Characteristics of resonance in heart rate variability stimulated by biofeedback. Applied Psychophysiology and Biofeedback. 2006;31(2):129-42.

[108] Park CL, Finkelstein-Fox L, Sacco SJ, Braun TD, Lazar S. How does yoga reduce stress? A clinical trial testing psychological mechanisms. Stress and Health. 2020.

[109] Heilbronn F. The use of hatha yoga as a strategy for coping with stress in management development. Management Education and Development. 1992;23(2):131-9.

[110] Rizzolo D, Zipp GP, Stiskal D, Simpkins S. Stress management strategies for students: The immediate effects of yoga, humor, and reading on stress. Journal of College Teaching \& Learning (TLC). 2009;6(8).

[111] Telles S, Sharma SK, Singh N, Balkrishna A. characteristics of Yoga Practitioners, Motivators, and Yoga Techniques of choice: a cross-sectional study. Frontiers in Public Health. 2017;5:184. 